\title{
Papers
}

\section{Effectiveness of Ginkgo biloba in treating tinnitus: double blind, placebo controlled trial}

\author{
Shelley Drew, Ewart Davies
}

\begin{abstract}
Objective To determine whether Ginkgo biloba is effective in treating tinnitus.

Design Double blind, placebo controlled trial using postal questionnaires.

Participants 1121 healthy people aged between 18 and 70 years with tinnitus that was comparatively stable; 978 participants were matched (489 pairs). Intervention 12 weeks' treatment with either $50 \mathrm{mg}$ Ginkgo biloba extract LI 1370 three times daily or placebo.

Main outcome measures Participants' assessment of tinnitus before, during, and after treatment.

Questionnaires included items assessing perception of how loud and how troublesome tinnitus was. Changes in loudness were rated on a six point scale. Changes in how troublesome were rated on a five point scale.

Results There were no significant differences in primary or secondary outcome measures between the groups. 34 of 360 participants receiving active treatment reported that their tinnitus was less troublesome after 12 weeks of treatment compared with 35 of 360 participants who took placebo.

Conclusions $50 \mathrm{mg}$ Ginkgo biloba extract LI 1370 given 3 times daily for 12 weeks is no more effective than placebo in treating tinnitus.
\end{abstract}

\section{Introduction}

Tinnitus, or "ringing in the ears," is a common condition recognised as a problem by about $10 \%$ of the population and considered a major problem by about $0.5 \%$. ${ }^{1}$ There are no effective pharmacological treatments for tinnitus. Because tinnitus is considered to have a number of underlying causes, it is unlikely that a single treatment will be effective for all patients. Therefore, trials of treatments for tinnitus need to be capable of identifying treatments that may help only a subgroup of those with tinnitus. Such trials should be well controlled and include large numbers of patients. Previous trials have failed to meet these criteria and have produced inconsistent and ambiguous results. ${ }^{2}$

Extracts from the Ginkgo biloba tree have been used in Chinese medicine for thousands of years. Recently, however, Ginkgo biloba extracts have become commonly available in health food stores throughout the United Kingdom; Ginkgo biloba is one of the top 10 selling herbs in health food stores in the United States. ${ }^{3}$
High quality, standardised extracts from the leaves of the tree have been shown to have significant therapeutic effect on the symptoms of cerebral insufficiency, including memory disturbances and other cognitive deficits such as tinnitus. ${ }^{45}$ In Germany and several other European countries Ginkgo biloba is registered as a drug and is among the top five most commonly prescribed medications: more than five million prescriptions were written in Germany in $1998 .{ }^{6}$ In Germany, Ginkgo biloba extracts must meet the requirements of the 1994 German Commission E monograph which specifies what the extract must contain. ${ }^{7}$ This ensures that extracts that are prescribed are almost identical to those which have been shown to be effective in clinical trials. Extracts sold in the United Kingdom, however, are not classed as drugs and so are not required to conform to the standards of those that have been shown to be effective. Thus, there is a large variety of extracts available.

Determining whether Ginkgo biloba is effective in treating tinnitus is hindered by the lack of evidence. Prospective studies carried out to determine whether it is effective in treating tinnitus without accompanying symptoms of cerebral insufficiency have provided inconsistent results. ${ }^{2}$ None the less, Ginkgo biloba is frequently suggested as a possible treatment for tinnitus in the press, and many people with tinnitus are using a variety of products on the basis of limited evidence.

In this study a standardised extract of Ginkgo biloba (LI 1370, Lichtwer Pharma, Berlin, Germany) was used in a large, controlled trial to determine whether it is effective in treating tinnitus. This is one of the most popular brands sold in the United Kingdom, and the extract conforms to the requirements of the German Commission E monograph.

\section{Participants and methods}

\section{Participants}

Participants were recruited through advertisements in the national press in the United Kingdom and the British Tinnitus Association's publication, Quiet. Altogether, 1121 participants were selected from the original 8667 applicants and matched when possible. The criteria for creating matched pairs were that participants had to be the same sex, be similar ages $(\leqslant 10$ years difference), and the duration of tinnitus had to be $\leqslant 5$ years. The progress of patients from recruitment
Pharmacology
Department,
Division of
Neuroscience,
University of
Birmingham,
Birmingham
B15 2TT
Shelley Drew
research associate
Ewart Davies
senior lecturer
Correspondence to:
S Drew
s.j.drew@bham.
ac.uk
BMJ 2001;322:1-6 


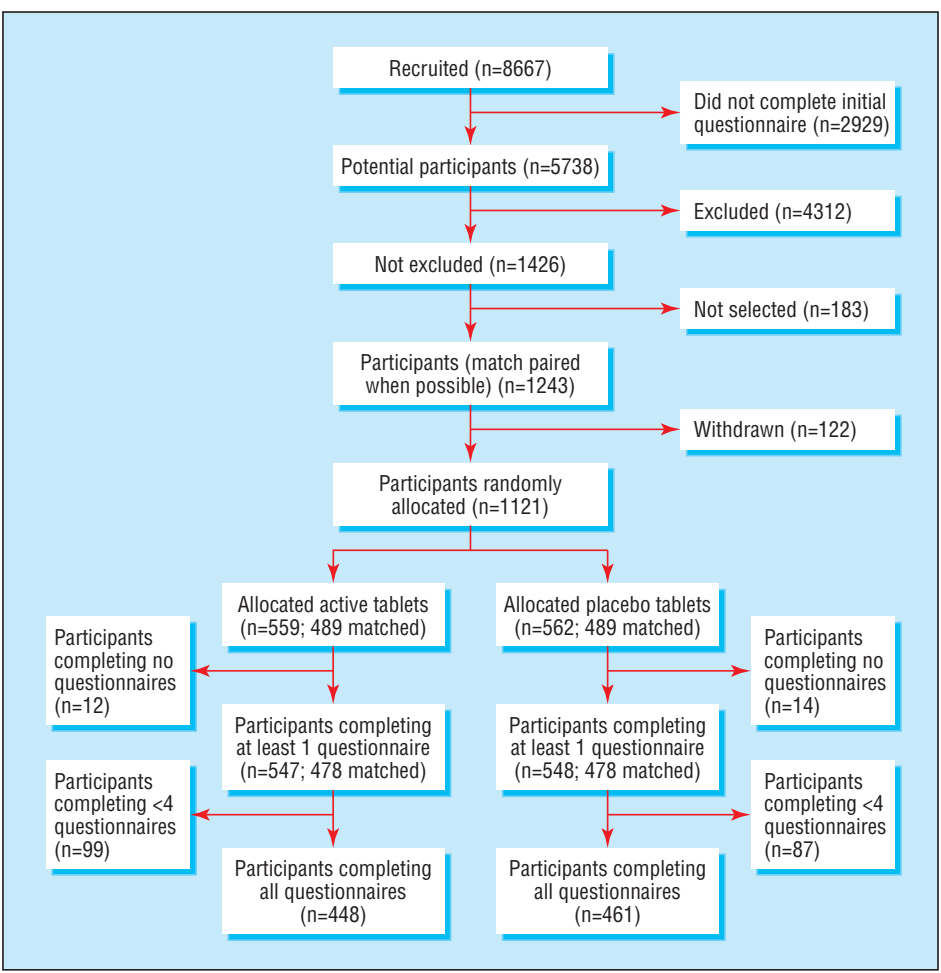

Fig 1 Progress of participants through the trial

through the duration of the trial is shown in figure 1 . Exclusion criteria are shown in the box.

\section{Methods}

This double blind, placebo controlled trial was carried out entirely by mail and telephone. Patients were contacted by telephone only to resolve problems or answer inquiries. All procedures were approved by the local ethics committee (South Birmingham Health Authority). Calculations of sample size were based on previous unmatched and categorical data because matched and ordinal data were not available. ${ }^{8}$ Assuming that there would be a significant improvement in tinnitus in 30\% of participants taking placebo, the calculations predicted that it would be necessary to have 496 patients in each group to show a $10 \%$ improvement over placebo among those taking active treatment with a power of $90 \%$ at the 0.05 significance level. The sample size was set to account for withdrawals.

Participants were paired according to the criteria described. Each pair was then allocated two numbers

\section{Exclusion criteria}

Patients were excluded if

They were $<18$ years or $>70$ years old

They were pregnant or trying to get pregnant

They had previously taken Ginkgo biloba extract

They had had tinnitus for $<12$ months

They reported that their tinnitus had varied greatly in the six months

before the screening questionnaire

They had tried any treatment for tinnitus in the six months before completing the screening questionnaire (for example, acupuncture, homoeopathy, hypnotherapy, etc.)

They were not generally in good health

They were taking anticoagulant drugs or antidepressants

They had abnormal blood pressure from a randomly arranged code. One number corresponded to placebo treatment and one to active treatment.

Tinnitus was assessed subjectively using questionnaires, and no audiological measurements were taken. Participants were sent four questionnaires. The first questionnaire was completed before treatment began, the second after 4 weeks of treatment, the third after the end of 12 weeks of treatment, and the fourth 2 weeks after treatment ended.

\section{Intervention}

The treatment was provided as 252 tablets containing $50 \mathrm{mg}$ of either Ginkgo biloba standardised extract LI 1370 (containing 25\% flavonoids, 3\% ginkgolides, and $5 \%$ bilobalides) or placebo (both provided by Lichtwer Pharma). Participants were instructed to take three tablets daily for 12 weeks. The extract and dose of Ginkgo biloba were chosen on the basis of the results of previous trials in which this dose of this extract had been reported to be effective in treating cerebral insufficiency. ${ }^{5}$ Placebo tablets were identical to the active tablets in shape, size, colour, and packaging.

The tablets were dispensed in coded bottles, and treatment allocation was masked. The allocation procedure ensured that all matched participants received active or placebo tablets without the code being identified. The blinding for any one pair of participants could be removed without jeopardising the remainder of the code.

\section{Outcome measures}

The scales used in the questionnaires were devised for this study and based on previously validated self assessment scales. ${ }^{9}$ The questionnaires contained 21 questions about the severity of tinnitus. These were divided into three groups: measures of the perceived loudness of tinnitus, ratings of the participant's awareness of tinnitus and the ability to ignore it, and the impact of tinnitus. Summary scores were produced for each of the three groups of questions. These scores ranged from 0 to 12 for measures of loudness, from 0 to 22 for measures of awareness and ability to ignore, and from 0 to 39 for impact. The sum of the scores in these three groups was the total summary score. A summary score of 0 indicates that a participant has no tinnitus-that is, it is always silent, can always be ignored, and has no impact on the participant's life. The maximum summary score of 73 indicates that a participant has tinnitus that is severely troublesomefor example, it is always very loud, the participant can never ignore it, and it has a large impact on the participant's life. The summary scores from all the questions on severity were calculated and then compared between questionnaires for each participant to provide a measure of change in severity. The scoring system is shown in figure 2.

In the second, third, and fourth questionnaires there were three additional questions about change in tinnitus: participants were asked to assess whether they felt that their tinnitus had changed either in loudness or the amount of trouble that it caused since beginning the treatment (second and third questionnaires) or since completing it (fourth questionnaire). Participants were asked to score changes in the loudness of their tinnitus on a six point scale ranging from -4 
Scoring system for the questionnaire

For each question $(Q)$ there were 2-10 possible answers $(A)$; participants were asked to choose one. The score (S) given for each answer is shown in square brackets. Summary scores were calculated either by adding together the score from several questions in each questionnaire (for example, the summary score of secondary outcome measures is the sum of all the scores on the questions on loudness, awareness of or ability to ignore tinnitus, and impact of tinnitus) or by adding together scores on the same question from two or more questionnaires (for example, the summary compliance score would be the sum of the scores of the question on compliance from the second and third questionnaires).

\section{A) Primary outcome measurements}

Loudness change (scores: -4 to 6 )

Q: Do you think that* the treatment you have taken as part of the trial has made your tinnitus:

A: much louder slightly louder unchanged slightly quieter much quieter disappear
S: $[-4]$
$[-2]$
[0]
[2]
[4]

[6]

Troublesome Nature Change (scores: -4 to 4 )

Q: Do you think that ${ }^{\star}$ the treatment has made your tinnitus:

A: much more slightly more unchanged slightly less much less troublesome troublesome troublesome troublesome
S: $[-4]$
$[-2]$
[0]
[2]
[4]

( ${ }^{\star}$ The word "stopping" is included here in questionnaire 4)

B) Secondary outcome measurements: Total summary score: 0-73

Loudness questions (scores: 0 to 12)

Q: How loud is your most troublesome noise? A: Silent Slight Moderate Loud Very loud

\begin{tabular}{|c|c|c|c|c|}
\hline Q: a) At its loudest & S: [0] & [1] & [2] & [3] \\
\hline Q: b) At its quietest & S: [0] & [1] & [2] & [3] \\
\hline Q: c) Most commonly & S: $[0]$ & [1] & [2] & [3] \\
\hline
\end{tabular}

Awareness/ability to ignore tinnitus (total score 0 to 22)

$Q$ : What percentage of your waking hours are you aware of your current tinnitus?:

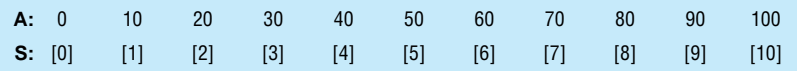

Q: How much are you able to ignore your tinnitus

Q: a) When actively doing something (talking or watching TV)

A: Not at all Slightly Moderately Greatly

Q:in a noisy room?

[2] [1] [0]

Q: b) When inactive Q:in a quiet room? S:

[2] [1] Q:in a noisy room?

s: $[3]$

[2] [1] [0]

Impact questions (total score 0 to 39)

$Q$ : How much does your current tinnitus:

$\mathbf{Q}$ : a) annoy you?

$\mathbf{Q}$ : b) worry you?

Q: c) depress you?

Q: d) discomfort you?

Q: e) make you feel tired or ill?

$Q:$ f) make it difficult to relax?

Q: g) make you irritable?

Q: h) affect your concentration?

Q: i) affect you hearing ability?

Q:in a quiet room?

Q:in a noisy room?

Q: j) make sleeping difficult?

Q: k) affect your social life?

Q: I) affect your overall quality of life?

A: Not at all Slightly Moderately Greatly

$\begin{array}{lllll}\text { S: } & {[0]} & {[1]} & {[2]} & {[3]} \\ \text { S: } & {[0]} & {[1]} & {[2]} & {[3]} \\ \text { S: } & {[0]} & {[1]} & {[2]} & {[3]} \\ \text { S: } & {[0]} & {[1]} & {[2]} & {[3]} \\ \text { S: } & {[0]} & {[1]} & {[2]} & {[3]} \\ \text { S: } & {[0]} & {[1]} & {[2]} & {[3]} \\ \text { S: } & {[0]} & {[1]} & {[2]} & {[3]} \\ \text { S: } & {[0]} & {[1]} & {[2]} & {[3]} \\ & & & & \\ \text { S: } & {[0]} & {[1]} & {[2]} & {[3]} \\ \text { S: } & {[0]} & {[1]} & {[2]} & {[3]} \\ \text { S: } & {[0]} & {[1]} & {[2]} & {[3]} \\ \text { S: } & {[0]} & {[1]} & {[2]} & {[3]} \\ \text { S: } & {[0]} & {[1]} & {[2]} & {[3]}\end{array}$

Fig 2 Scoring system for questionnaire (treatment has made tinnitus much louder) to 6 (treatment has made it disappear). Changes in the amount of trouble caused were scored on a five point scale ranging from -4 (treatment has made tinnitus much more troublesome) to 4 (treatment has made it much less troublesome). The score for "no change" was in the middle or near the middle of the scale. Mean scores were compared between treatment groups. Additionally, the total number of participants reporting that their tinnitus had improved was compared between groups.
C) Other measurements

Tinnitus variability questions (2 questions, summary score 0 to 6 )

Q: How often does your most troublesome A: Not at all Weekly Daily Hourly noise vary in loudness?

S: [0] [1] [2] [3]
noise vary in loudness?

S: $[0] \quad[1] \quad[2] \quad[3]$

Cerebral insufficiency questions (summary score -24 to 24 )

$Q$ : Have you experienced any changes in any of the following since starting* the treatment?

A: Much worse Worse Unchanged Better Much better

Q: a) forgetfulness $\quad$ S: $\quad[-2] \quad[-1] \quad[0] \quad[1] \quad[2]$

Q: b) concentration S: $[-2] \quad[-1] \quad[0] \quad[1] \quad[1]$

Q: c) lack of attention S: $\quad[-2] \quad[-1] \quad[0] \quad[1] \quad\left[\begin{array}{lll}{[1]} & {[1]}\end{array}\right.$

Q: d) dizziness $\quad$ S: $[-2] \quad[-1] \quad[0] \quad[1] \quad\left[\begin{array}{llll}1 & {[1]} & {[0]}\end{array}\right]$

Q: e) tiredness $\quad$ S: $\quad[-2] \quad[-1] \quad[0] \quad[1] \quad[2]$

Q: g) sleeping problems S: $[-2] \quad[-1] \quad[0] \quad[1]$

Q: h) lack of drive $\quad$ S: $[-2] \quad[-1] \quad[0] \quad[1]$

Q: i) depressive moods $\quad$ S: $\quad[-2] \quad[-1] \quad[0] \quad[1] \quad[-1]$

Q: j) headaches $\quad$ S: $[-2] \quad[-1] \quad[0] \quad[1]$

Q: k) restlessness $\quad$ S: $\left[\begin{array}{lllll}{[-2]} & {[-1]} & {[0]} & {[1]} & {[2]}\end{array}\right.$

Q: I) anxiety $\quad$ S: $[-2] \quad[-1] \quad[0] \quad[1]$

( The word "starting" is replaced with "stopping" in questionnaire 4)

Compliance question (summary score from Questionnaires 2 and 3;0 to 8)

Questionnaires 2 and 3 only:

Q: How well do you think you complied with the instructions for taking the tablets?

S: [4] [2] [0]

Side effects question (no scores for this question)

Q: Have you noticed any other effects of *the treatment?

A: No Yes (a good effect) Yes (a bad effect)

S: $[\mathrm{N}] \quad[\mathrm{G}]$

( "Stopping" included here in questionnaire 4)
Q: f) stamina $\quad$ S: $[-2] \quad[-1] \quad[0]$

A: Well Moderately Not well tinnitus, compliance with the treatment regimen, and side effects were also included (fig 2). Summary scores were again compared between groups. Scores for the 
Table 1 Characteristics of participants

\begin{tabular}{lcc} 
& \multicolumn{2}{c}{ Treatment group } \\
\cline { 2 - 3 } & Active (n=489) & Placebo (n=489) \\
\hline Mean (SD) age (years) & $52.9(9.3)$ & $53.0(9.3)$ \\
\hline Mean (SD) duration of tinnitus (years) & $10.0(8.3)$ & $10.1(8.3)$ \\
\hline No (\%) men & $338(69)$ & $338(69)$ \\
\hline No (\%) women & $151(31)$ & $151(31)$ \\
\hline $\begin{array}{l}\text { Mean (SD) summary score for } \\
\text { compliance }\end{array}$ & $7.2(1.5)$ & $7.3(1.4)$ \\
\hline $\begin{array}{l}\text { *Scores for compliance ranged from 0 (instructions not followed well) to } 8 \\
\text { (instructions followed well). }\end{array}$
\end{tabular}

variability of tinnitus ranged from 0 (not at all variable) to 6 (varies hourly). Scores for cerebral insufficiency ranged from -24 (all symptoms much worse) to 24 (all symptoms much better). Scores for compliance with treatment ranged from 0 (instructions not followed well) to 8 (instructions followed well).

\section{Data analysis}

Data were analysed on an intention to treat basis wherever possible. Data entry and initial analyses were carried out by a researcher blinded to the participant's allocation. Statistical analysis was carried out using SPSS version 9.0 for Windows except for the calculation of confidence intervals for proportions; these were calculated using the equations given by Gardner and Altman. ${ }^{10}$ All reported $\mathrm{P}$ values are two tailed. Paired data were compared between treatment groups using McNemar's test and paired sample $t$ tests.
Unmatched analyses did not provide any additional information and have therefore been excluded from this paper.

\section{Results}

The number of participants who were excluded or who withdrew from the study is shown in figure 1 . Altogether 1121 participants were allocated to treatment (559 to active treatment and 562 to placebo); of these, 956 participants were paired. Characteristics of the paired participants are shown in table 1. Analysis of the side effects of treatment was carried out using data from all 489 matched pairs. However, 26 participants completed no questionnaires so all other analyses were carried out on the remaining 478 pairs in which both members completed at least one questionnaire. The total number of participants was considerably smaller for the matched analyses than for the unmatched analyses. This was because matched analyses required complete data from each member of the pair and was therefore more affected by missing or incomplete data.

\section{Outcome measures}

The proportion of pairs reporting an improvement in how troublesome they found their tinnitus at 4 or 12 weeks or a worsening at 14 weeks with either active or placebo treatment is shown in table 2. There were no significant differences between the treatments at weeks 4,12 , and 14 .

Table 2 Paired comparison of the No and proportion of pairs in each group (active treatment or placebo) reporting an improvement in tinnitus. Treatment was considered to have been successful if participants reported an improvement at 4 or 12 weeks or a worsening at 14 weeks (2 weeks after stopping treatment)

\begin{tabular}{|c|c|c|c|c|c|c|c|c|}
\hline \multirow{2}{*}{$\begin{array}{l}\text { Time (No of } \\
\text { pairs) }\end{array}$} & \multirow{2}{*}{$\begin{array}{l}\text { Neither } \\
\text { treatment } \\
\text { successful }\end{array}$} & \multirow{2}{*}{$\begin{array}{l}\text { Active treatment } \\
\text { unsuccessful/ } \\
\text { placebo } \\
\text { successful }\end{array}$} & \multirow{2}{*}{$\begin{array}{l}\text { Active treatment } \\
\text { successful/ } \\
\text { placebo } \\
\text { unsuccessful }\end{array}$} & \multirow{2}{*}{$\begin{array}{l}\text { Both active } \\
\text { and placebo } \\
\text { successful }\end{array}$} & \multicolumn{2}{|c|}{$\begin{array}{l}\text { Proportion of treatment } \\
\text { successful (\%) }\end{array}$} & \multirow[b]{2}{*}{$95 \% \mathrm{Cl}^{*}$} & \multirow[b]{2}{*}{ McNemar's test } \\
\hline & & & & & Placebo & Active & & \\
\hline 4 weeks (414) & 367 & 27 & 18 & 2 & 7.0 & 4.8 & -5.3 to 1.0 & 0.2 \\
\hline 12 weeks (360) & 292 & 34 & 33 & 1 & 9.7 & 9.4 & -4.7 to 4.2 & 1.0 \\
\hline 14 weeks (354) & 275 & 32 & 40 & 7 & 11.0 & 13.3 & -2.4 to 7.0 & 0.4 \\
\hline
\end{tabular}

${ }^{*}$ Comparison between results of active treatment and placebo treatment.

Table 3 Mean differences (SD; 95\% confidence interval) in scores between matched pairs of participants with tinnitus

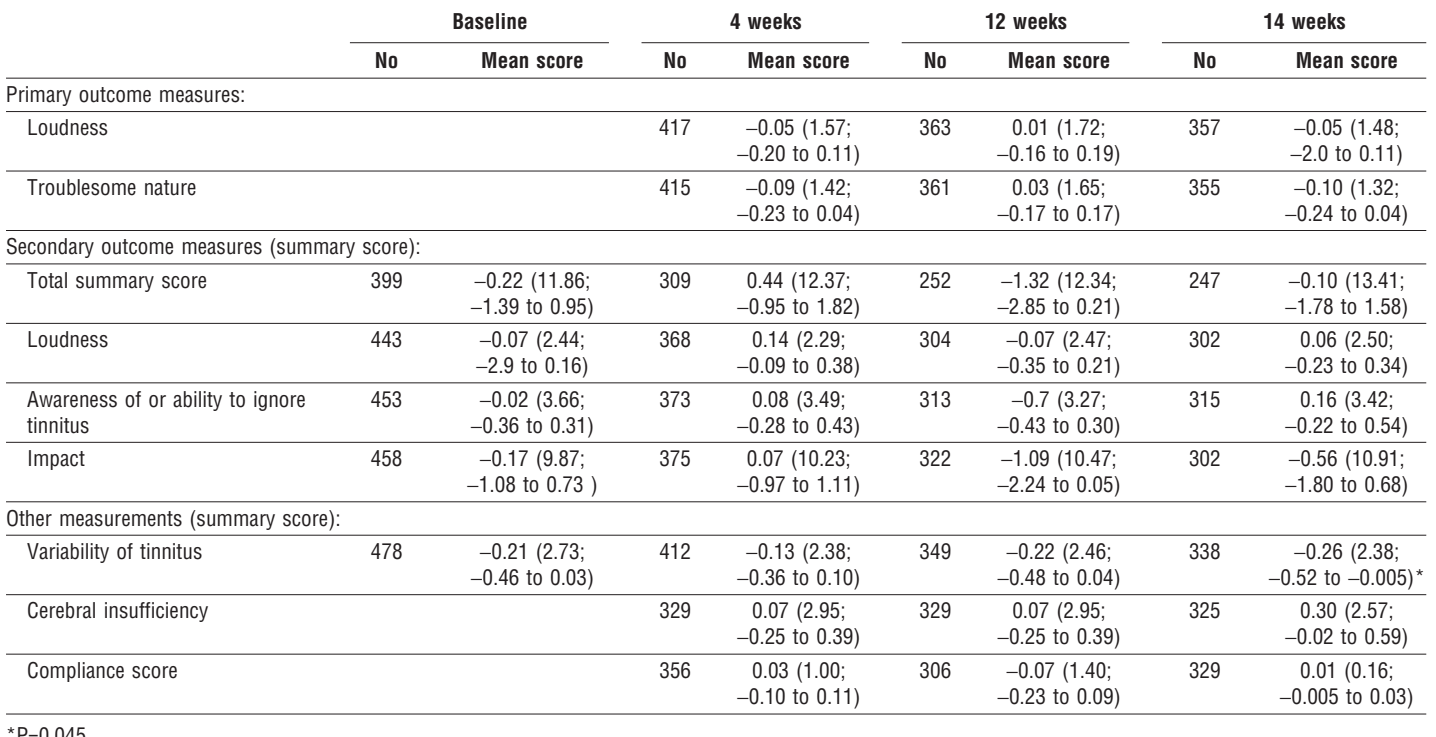


Table 4 Mean difference (SD; 95\% confidence interval) between pre-treatment (baseline) scores and scores at 12 weeks between matched participants

\begin{tabular}{lcc} 
& $\begin{array}{c}\text { No. of } \\
\text { participants }\end{array}$ & Mean difference \\
\hline Secondary outcome measures: & & \\
\hline Total summary score & 212 & $-0.22(6.55 ;-1.11$ to 0.67$)$ \\
\hline Loudness & 279 & $-0.08(1.58 ;-0.27$ to 0.11$)$ \\
\hline $\begin{array}{l}\text { Awareness of or ability to } \\
\text { ignore tinnitus }\end{array}$ & 297 & $-0.15(3.21 ;-0.52$ to 0.22$)$ \\
\hline$\quad$ Impact & 300 & $-0.15(5.37 ;-0.76$ to 0.46$)$ \\
\hline Other measurements: & & \\
\hline Tinnitus variability & 279 & $-0.08(1.58 ;-0.27$ to 0.11$)$ \\
\hline
\end{tabular}

Paired sample $t$ tests identified no significant difference between the two groups with respect to primary outcome measures, secondary outcome measures, compliance, or cerebral insufficiency (tables 3 and 4 ).

The number and type of side effects reported during the trial are shown in table 5. The incidence of adverse events was similar between the treatment groups but the incidence of beneficial effects was not (beneficial effects reported by $24 / 489(4.9 \%)$ in the active treatment group $v 11 / 489(2.2 \%)$ in the placebo group). This was statistically significant (95\% confidence interval $0.4 \%$ to $4.9 \%$ ). Subgroup analyses failed to find any significant differences between groups with respect to different types of beneficial effects.

\section{Discussion}

Ginkgo biloba extract LI 1370 had no greater therapeutic effect than placebo in treating tinnitus. In addition, other symptoms of cerebral insufficiency were not significantly affected by the treatment (table 3 ). The results from this trial are similar to some reports and contrast with others. ${ }^{2}$ This study differs from other trials in many ways. The main strength of this study was its large size and controlled design. Previous trials involved fewer than 300 subjects and often lacked adequate controls. ${ }^{2}$ This study achieved its large sample size using a simple approach to data collection (postal questionnaires). A weakness of this approach, however, was that contact with participants was minimal, and participants were probably provided with less support than offered in other trials. The lack of contact with participants may explain the comparatively low response to placebo in this study, but it should not have affected the overall result because it would have affected both groups equally. A matched pair method has not previously been used to study the efficacy of Ginkgo biloba extract, and it was probably an unnecessary and disadvantageous complication of this trial because analyses of the matched pairs used considerably smaller numbers than the unmatched analyses. None the less, unmatched analyses were also carried out (but not presented here), and the pairing process did ensure that treatment groups were similar.

Methods of assessing tinnitus have differed between trials, although most have used a simple, subjective measurement of change in tinnitus, similar to the primary outcome measure used in this study. Our method of assessing tinnitus was thorough, enabled small changes to be identified, and concentrated on the most clinically relevant measurement for this condition

Table 5 Adverse and beneficial effects of Ginkgo biloba treatment for tinnitus among 489 matched pairs of participants

\begin{tabular}{|c|c|c|c|c|c|c|c|c|}
\hline & \multicolumn{4}{|c|}{ Side effects } & \multicolumn{2}{|c|}{$\begin{array}{l}\text { Proportion (\%) reporting } \\
\text { side effects }\end{array}$} & \multirow[b]{2}{*}{$95 \% \mathrm{Cl}^{*}$} & \multirow[b]{2}{*}{$\begin{array}{l}\text { McNemar's } \\
\text { test }\end{array}$} \\
\hline & $\begin{array}{l}\text { Reported by } \\
\text { neither } \\
\text { participant }\end{array}$ & $\begin{array}{c}\text { Reported only } \\
\text { by participant } \\
\text { taking } \\
\text { placebo }\end{array}$ & $\begin{array}{c}\text { Reported only } \\
\text { by participant } \\
\text { taking active } \\
\text { treatment }\end{array}$ & $\begin{array}{l}\text { Reported by } \\
\text { both }\end{array}$ & $\begin{array}{l}\text { Placebo } \\
\text { group }\end{array}$ & $\begin{array}{l}\text { Active } \\
\text { treatment } \\
\text { group }\end{array}$ & & \\
\hline \multicolumn{9}{|l|}{ Beneficial effects: } \\
\hline General well being & 482 & 2 & 5 & 0 & 0.4 & 1.0 & -0.4 to 1.7 & 0.45 \\
\hline Improved circulation & 483 & 1 & 5 & 0 & 0.2 & 1.0 & -0.2 to 1.8 & 0.22 \\
\hline Hearing better & 484 & 2 & 3 & 0 & 0.4 & 0.6 & -0.7 to 1.1 & 1.00 \\
\hline$\geqslant 1$ other good side effects & 467 & 7 & 14 & 1 & 1.6 & 3.1 & -0.4 to 3.3 & 0.19 \\
\hline $\begin{array}{l}\text { No of pairs reporting } \geqslant 1 \\
\text { beneficial effect of treatment } \dagger\end{array}$ & 456 & 9 & 22 & 2 & 2.2 & 4.9 & 0.4 to 4.9 & 0.03 \\
\hline \multicolumn{9}{|l|}{ Adverse effects: } \\
\hline Gastrointestinal upset & 460 & 14 & 14 & 1 & 3.1 & 3.1 & -2.1 to 2.1 & 1.00 \\
\hline $\begin{array}{l}\text { Worsening of blocking or pressure } \\
\text { in ear }\end{array}$ & 475 & 4 & 10 & 0 & 0.8 & 2.1 & -0.3 to 2.7 & 0.18 \\
\hline $\begin{array}{l}\text { Dizziness, lightheadedness, or } \\
\text { nausea }\end{array}$ & 476 & 7 & 6 & 0 & 1.4 & 1.2 & -1.6 to 1.2 & 1.00 \\
\hline Headache & 481 & 4 & 4 & 0 & 0.2 & 0.8 & -1.1 to 1.1 & 1.00 \\
\hline Mouth ulcer, dryness, bad taste & 480 & 6 & 3 & 0 & 1.2 & 0.6 & -1.8 to 0.6 & 0.51 \\
\hline Sleep or dreams worse & 482 & 3 & 4 & 0 & 0.6 & 0.8 & -0.9 to 1.3 & 1.00 \\
\hline Flushing or redness of the face & 484 & 4 & 1 & 0 & 0.8 & 0.2 & -1.5 to 0.3 & 0.37 \\
\hline Skin worse (dry, itchy, spots) & 484 & 3 & 2 & 0 & 0.6 & 0.4 & -1.1 to 0.7 & 1.00 \\
\hline Awareness of heartbeat & 483 & 3 & 3 & 0 & 0.6 & 0.6 & -1.0 to 1.0 & 1.00 \\
\hline Hearing worse & 485 & 1 & 3 & 0 & 0.2 & 0.6 & -0.4 to 1.2 & 0.62 \\
\hline Hyperacusis & 487 & 2 & 0 & 0 & 0.4 & 0.0 & -1.0 to 0.2 & 0.50 \\
\hline$\geqslant 1$ other adverse side effects $\ddagger$ & 472 & 7 & 9 & 1 & 1.6 & 2.0 & -1.2 to 2.0 & 0.80 \\
\hline $\begin{array}{l}\text { No of pairs reporting } \geqslant 1 \text { adverse } \\
\text { effect of treatment }\end{array}$ & 392 & 43 & 46 & 8 & 10.4 & 11.0 & -3.2 to 4.4 & 0.83 \\
\hline
\end{tabular}

${ }^{\star}$ Comparison between results of active treatment and placebo treatment.

tOther beneficial effects included improvements in desire for sex; improvement in impotence; easier breathing; and improvements in symptoms of irritable bowel syndrome, sleep and dreams, concentration and reactions, headaches, appetite, stress, illness (colds or flu), skin, bladder control, blocked ears or pressure in ears, and dizziness.

$\ddagger$ Other adverse effects included a decrease in sexual desire, difficulty breathing, watering eyes, worsening of eyesight, more frequent urination or discoloration of urine, worsening of stiffness in the joints, night sweats, worsening of stress, anaemia, and loss of appetite. 


\section{What is already known on this topic}

Ginkgo biloba extract has been shown to have therapeutic effects on symptoms of cerebral insufficiency including memory disturbances and other cognitive deficits, such as tinnitus

Whether it is effective in treating tinnitus alone (without other accompanying symptoms of cerebral insufficiency) is not clear

Previous studies were small, often poorly controlled, and have had inconsistent results

\section{What this study adds}

This large, double blind, placebo controlled trial found that Ginkgo biloba extract was no more effective than placebo in treating tinnitus alone

(that is, perceived changes in tinnitus). Another strength of this study was that this treatment regimen has been shown to be effective in cerebral insufficiency. Additionally, a measure of the symptoms of cerebral insufficiency was included in the design to determine whether any improvements in tinnitus were associated with improvements in symptoms of cerebral insufficiency.

Most previous trials have used similar treatment doses and been of similar duration, but the methods of administration and the composition of the extract have varied. ${ }^{5}$ Therefore, it is possible that at least some of the inconsistencies identified by previous studies may be related to the different types of Ginkgo biloba extract that were used. Measurements of other symptoms of cerebral insufficiency have not been made in previous trials. Since neither tinnitus nor other symptoms of cerebral insufficiency were significantly improved in this study, it would be interesting to learn whether trials in which Ginkgo biloba was found to be effective in tinnitus showed that participants had any improvements in other symptoms of cerebral insufficiency. It is tempting to speculate that positive trials have involved a greater number of patients who have cerebral insufficiency and thus improvements in tinnitus were related to an improvement in cerebral insufficiency rather than being a direct effect of treatment.

This study has not shown that Ginkgo biloba is effective in treating tinnitus. The extract used in this study (LI $1370150 \mathrm{mg}$ /day for 12 weeks) seems to be ineffective in treating tinnitus alone, but it may be effective in treating tinnitus in patients who also have other symptoms of cerebral insufficiency. The composition of other extracts or the use of other treatment regimens, or both, might be effective in treating tinnitus alone but there is little evidence of this.

Finally, we would like to raise another issue. Although an effective pharmacological treatment for tinnitus is unavailable, it may be in patients' interest to be advised to take a substance that has a reputation for effectiveness irrespective of the pharmacological value of the recommendation, particularly if the substance has few side effects, as is the case with Ginkgo biloba. Should we consider aiming for a placebo response in treating patients with tinnitus until an effective pharmacological treatment is available?

We thank Mr $\mathrm{H}$ Ross for his statistical advice and technical assistance; Dr J Simpson, Mr P Josling, and Dr R Middleton for their help and advice; and members of the Birmingham BTA group and Mr P Hopkins for their administrative help.

Contributors: ED initiated the research. SD and ED designed the study. SD conducted the research and analysed the data. The paper was co-written by the authors. SD is guarantor for the paper.

Funding: This work was funded by the British Tinnitus Association in conjunction with Lichtwer Pharma UK, manufacturer of the extract used in this study.

Competing interests: The study was financed (two years' salary for $\mathrm{SD}$ and running costs) by a contract between the British Tinnitus Association and Lichtwer Pharma GmbH, Berlin, who also supplied the Ginkgo biloba extract and placebo tablets.

1 Davis A, Rafaie EA. Epidemiology of tinnitus. In: Tyler RS, ed. Tinnitus handbook. San Diego, CA: Singular Press, 2000.

2 Ernst E, Stevinson C. Ginkgo biloba for tinnitus: a review. Clin Otolaryngol 1999;24:164-7.

3 Winslow LC, Kroll DJ. Herbs as medicines. Arch Intern Med $1998 ; 158: 2192-9$.

4 Soholm B. Clinical improvement of memory and other cognitive functions by Ginkgo biloba: review of relevant literature. Adv Ther 1998;15:54-65.

5 Kleijnen J, Knipschild P. Ginkgo biloba for cerebral insufficiency. Br J Clin Pharmacol 1992;34:352-8.

6 Curtis-Prior P, Vere D, Fray P. Therapeutic value of Ginkgo biloba in reducing symptoms of decline in mental function.J Pharm Pharmacol 1999;51:535-41.

7 Blumenthal M, Busse WR, Goldberg A, Gruenwald J, Hall T, Riggins CW, et al, eds. The complete German commission E monographs: therapeutic guide to herbal medicines. Austin, TX: American Botanical Council, 1998.

8 Duckert LG, Rees TS. Placebo effect in tinnitus management. Otolaryngol Head Neck Surg 1984;92:697-9.

9 Axelsson A, Coles R, Erlandsson S, Vernon MM, Vernon J. Evaluation of tinnitus treatment: methodological aspects. J Audiological Med 1993;2:141-50.

10 Gardner MJ, Altman DG. Calculating confidence intervals for proportions and their differences. In: Gardner MJ, Altman DG, eds. Statistics with confidence: confidence intervals and statistical guidelines. London: BMJ Publishing, 1989.

(Accepted 11 October 2000) 